\title{
RELAÇÕES ENTRE O ESTUDO E O TRABALHO EM CUBA: UM MODELO PERMEADO POR MANIFESTAÇÕES DO MARXISMO-LENINISMO E DO IDEÁRIO DE MARTÍ
}

\author{
Maria do Carmo Luiz Caldas Leite ${ }^{1}$
}

\section{RESUMO:}

O artigo está vinculado à pesquisa realizada em Cuba, no período de 2001 a 2009, que procurou investigar as relações entre trabalho e educação no Sistema Nacional de Ensino cubano. O que se busca é discutir a percepção formativa de unidade entre o caráter laboral e a escola, dentro de uma concepção marxista permeada pelo ideário pedagógico de José Martí, envolvendo os vários subsistemas da Educação, dentre eles a Formação e o Aperfeiçoamento do Pessoal Pedagógico, com base nas experiências acumuladas em Cuba, desde 1959. O recorte prioriza a análise da conjuntura relacionada à aplicabilidade dos princípios de estudo e trabalho, que exercem significativa influência na educação dentro das transformações em curso nos centros escolares da Ilha, a partir do início do novo milênio. Para tal, destacam-se os trabalhos de Castellanos Simons (2001) e Rojas Arce (2005), fundamentais no embasamento desta investigação.

Palavras-chave: Educação em Cuba; Trabalho e Educação; Formação de Professores.

\section{RELATIONS BETWEEN WORK AND STUDY IN CUBA: a model for expressions of implied Marxism-Leninism and the ideals of MARTI}

\section{ABSTRACT:}

The article is related to the research conducted in Cuba from the year 2001 to 2009, which investigated the relationship between work and education in the Cuban National Educational System. The objective is to discuss the perception of union in work character and school, within a Marxist ideology permeated by the teaching of José Martí, involving the various Education subsystems, including the Training and Improvement of Teaching Staff, based on accumulated experiences in Cuba since 1959. The text emphasizes the applicability analysis of the principles associated to study and work, which exert significant influence on education in the ongoing changes taking place in schools on the island, since the beginning of the new millennium. To this end, the work of Castellanos Simons (2001) and Rojas Arce (2005) are highlighted as the fundamental basis of this investigation.

Keywords: Education in Cuba, Labor and Education, Teacher Education.

\section{INTRODUÇÃO}

\author{
"La pluma debería manejarse por la tarde \\ en las escuelas; pero por la mañana, la \\ azada" \\ (José Martí).
}

Com os câmbios ocorridos na década de 80 , sob o ingênuo festejar da queda do muro de Berlin, o mundo viveu significativas experiências. No balanço de Kohan (2005, p.XXI), o marxismo oficial do antigo campo socialista, "já não tinha nem a autoridade, nem o poder de convencimento, que nunca deveriam ter perdido", e na prática, isso 
significou o fechamento do período histórico aberto com a Revolução de Outubro. As transformações na esfera político-social em Cuba estão influenciadas por causas relacionadas a esse desmoronamento, ainda sem um contexto sedimentado que permita alusões conclusivas.

Como consequência, a necessidade de mudanças na educação cubana foi desencadeada na etapa vivida na Ilha - o "Período Especial em Tempos de Paz" -, que teve início em 1991. A conjuntura de crise veio à tona, pois Cuba mantinha relações comerciais com os países do leste europeu, que alcançavam um percentual de aproximadamente $85 \%$, tanto na importação como na exportação. Essa ruptura teve sequelas marcantes ao despertar expectativas, no âmbito interno e no externo, pois abarcavam elementos capazes de corroer os valores socialistas. Em peculiar processo, a trama vivida no país oscila de forma periódica, entre o passado de lutas, o presente marcado por dificuldades e os interrogantes do futuro. A grande tensão foi motivada não só pelo desaparecimento da URSS, mas pela crise do pensamento ocidental, em razão dos desequilíbrios sociais e da perda de referenciais teóricos e históricos. Entretanto, na percepção deste estudo, com o advento de todas as mudanças, o modelo projetado para a educação cubana segue buscando consolidar a defesa dos princípios do socialismo, sendo que a intencionalidade declarada nas práticas e nos discursos é conseguir um alto nível de ideologização do ensino, valorizando um legado pedagógico autóctone, o qual contribuiu para a vindicação do trabalho e do estudo em um contexto distinto dos postulados neoliberais.

\section{CUBA: ANTECEDENTES HISTÓRICOS}

Todo hombre nace rey; la labor está en hallar en sí los útiles con que se hace el trono (José Martí).

Os processos educativos em Cuba, a última colônia da Espanha nas Américas, não podem ser entendidos sem o vínculo com as empreitadas históricas, que cunharam um imaginário de vertentes relativo às lutas de liberação. $\mathrm{O}$ caráter cubano emergiu de uma cultura de resistência, consolidada ao longo de trinta anos do século XIX, nas quais pereceram quatrocentos mil cubanos, ou seja, cerca de um terço da população da Ilha na época. Das guerras no século XIX, a historiografia cubana permitiu mais do que uma mera relação de assuntos bélicos. A análise dos conflitos, por diversos ângulos ideológicos, mostra que suas consequiências se estendem até os nossos dias.

Por mais concisa, a história de Cuba não pode ser escrita sem referências a José Martí (1853-1895). A trajetória de sua vida revolucionária o fez passar por vários países, proporcionando-lhe conhecimentos avançados para seu tempo. Defensor da escola obrigatória para Nuestra América, a síntese de seu ideário constitui, até hoje, um paradigma: o estudo, como direito de todos, asseguraria a liberdade de consciência, cultivando o homem para sua circunstância histórica. As estreitas relações, por ele pleiteada, entre educação, desenvolvimento ideológico da nacionalidade e formação do professor como um soldado da independência política são consideradas as bases da Educação em Cuba. Ainda que o legado de Martí esteja inserido num universo de desinformação sobre as lutas do povo cubano, ele abarca um referencial teórico - que evoluiu historicamente - distinguindo-se dos limites das correntes positivistas que adentraram na América Latina, no século XIX. Seu pensamento ultrapassava as fronteiras 
do utilitarismo e das cópias de outras latitudes desvinculados das realidades em que se aplicavam.

A Revolução Cubana não se inspirou em partidos clássicos, mas nos ideais organizativos de Martí, denunciante em sua época da notória desunião das forças progressistas. Como aponta Machado (1991, p. 22), a necessidade de construir um referencial hegemônico, em contraposição às forças do passado, fez da "Educação" e da "Revolução" processos mutuamente inclusivos, numa complexa dialética, capaz de contemplar as concepções vindas "do alto", com facetas iluministas, e a pressão vinda "de baixo", nas cobranças por radicalização do processo.

A relação que estabelecera Martí (1975, t. 8, p. 288) entre educação e emancipação - "ser culto é o único modo de ser livre" -, complementada com os pressupostos do movimento 26 de julho, serviu de base para o sistema orientado ao trabalho como princípio educativo, desde 1959. Ernesto Guevara buscou em Marx a necessidade da construção do homem novo, que produzisse sem a compulsão física de vender-se como mercadoria, num processo de auto-educação, com avanços interdependentes na formação técnica e ideológica. Assim, como caráter de defesa, recorreu-se à educação para edificar a nova sociedade, porque as transformações pedagógicas, em suas complexidades, representavam a desagregação de antigas concepções herdadas dos contextos anteriores. "Depois da revolução cubana deu-se máxima prioridade à educação e a saúde para fomentar o desenvolvimento humano" (UNESCO, 2005, p. 57).

\section{O SISTEMA NACIONAL DE ENSINO EM CUBA}

Na primeira etapa da Revolução, o grande desafio foi a alfabetização iniciada no período da luta insurrecional, a partir de 1956. Os movimentos alfabetizadores, trazendo dimensões de epopéia, constituíram a fonte motivadora das medidas revolucionárias, que iriam transformar a nação. O novo modelo, com base no Ativismo Pedagógico - quem sabe mais, ensina quem sabe menos - perpassou toda década de 60. Muitas das soluções imediatistas vigentes nesse período precisaram, mais tarde, ser retificadas. Em 1964, foram fundados os Institutos Superiores Pedagógicos - os ISPs -, com o objetivo de dar resposta à necessidade crescente de professores.

O segundo momento veio na década de 70, como resultado dos programas de massificação do ensino. Novos patamares, típicos de um sistema em expansão, revelaramse no processo, entre eles a carência de docentes, associada ao acesso pleno às escolas. $\mathrm{O}$ atual Sistema Nacional de Ensino - o SNE -, organizado nesta etapa, é integrado pela educação, formal e não-formal, organicamente articuladas, dentro dos subsistemas de Ensino Geral Politécnico e para o Trabalho, Educação Especial, Ensino Técnico e Profissional, Educação de Adultos, Formação do Pessoal Docente e Ensino Superior. O subsistema denominado Ensino Geral Politécnico e para o Trabalho constitui a base de todo o sistema educacional. A sua estrutura compreende o ensino pré-escolar, o ensino primário (do primeiro ao sexto grado), secundário (do sétimo ao nono grado) e médio, com três anos de duração.

Ao período de estancamento da economia cubana - década de 90 - seguiu-se uma etapa de reanimação, que permitiu ao Estado dar prioridade às ações voltadas à formação da cultura integral para toda a população. A Batalla de Ideas, um conjunto de projetos desencadeado em 1999, busca estratégias para garantir a igualdade de oportunidades e de possibilidades. Nesse processo são determinantes as organizações de massa, entre elas a Central de Trabalhadores, a Federação de Mulheres, os Comitês de Defesa da Revolução, a União de Jovens Comunistas e a Organização de Pioneiros José Martí, que congrega crianças e adolescentes até o nono grado. 
A universalização da educação superior em Cuba, inserida na Terceira Revolução Educacional, que abarca a Formação e o Aperfeiçoamento do Pessoal Pedagógico, está alicerçada nas microuniversidades. Atualmente, a educação e a cultura se multiplicam, na medida em que a universidade transcende seus muros institucionais e chega aos postos de trabalho, daqueles que se formam desde o desempenho profissional, nas localidades onde se encontram estabelecidos os centros laborais (CUBA, 2003, p. 36). A microuniversidade é uma escola, mas também pode ser um hospital ou uma fábrica, porque esta concepção não é exclusiva da formação do professor, uma vez que pressupõe colocar todos os universitários em contato com a realidade onde se desenvolve fisicamente a profissionalização. Segundo Alarcón de Quesada (2006, p. 1), “das 3.150 sedes universitárias, 22 estão instaladas em prisões, as quais foram convertidas em escolas".

Baseado no conceito do estudo como emprego, o Programa de Superação para Jovens entre 17 e 29 anos, com quatro dias de aulas por semana, é destinado aos que se encontram sem estudo e sem trabalho. De acordo Gómez Gutiérrez (2005, p. 7), incluídas as ciências médicas e pedagógicas, 48.406 egressos do programa matricularam-se nas diversas carreiras universitárias e o inédito da experiência está na ajuda econômica aos alunos.

\section{TRABALHO E EDUCAÇÃO EM CUBA}

Em Cuba, personalidades como Félix Varela, Enrique José Varona e José Martí assinalaram a importância de se alcançar uma educação ligada às experiências vitais dos seres humanos. Marx e Engels formularam cientificamente a necessidade de um ensino de caráter politécnico, no qual estudo e trabalho se vinculam, tornando possível o desenvolvimento das capacidades superiores, por exemplo, a linguagem e o pensamento, como princípio na formação integral do indivíduo. Desde a elaboração do Manifesto do Partido Comunista, entendeu-se que a educação e o trabalho tinham estreita relação. A pedagogia burguesa também havia se preocupado em estabelecer relações entre a escola e a atividade prática, mas, fundada na filosofia idealista, entendia essa relação de maneira genérica e abstrata.

A proposta formativa, mediante a unidade orgânica entre o caráter laboral e a escola, aparece dentro da concepção marxista e do ideal de educação "omnilateral". A preocupação com a formação para o trabalho, num processo educacional crítico, diz respeito não só ao aspecto técnico, mas também ao político e ao sociocultural. Tendo o trabalho como ponto de partida, busca-se aquilo que Gramsci chamou de "formação omnilateral do homem", a mais efetiva possibilidade para o exercício da cidadania na sociedade pósmoderna. Mediado pelo pensamento marxiano sobre o trabalho, como um processo histórico, Gramsci afirmava que os homens, em sua relação com a natureza, por meio de múltiplas atividades, criam a si mesmos, como indivíduos e como sociedade, além de propor um novo humanismo, intrinsecamente unido ao domínio cientifico e técnico do homem sobre a natureza (MANACORDA, 1990). Para Gramsci, o desenvolvimento omnilateral só seria possível se a totalidade das forças produtivas fosse dominada pelos A proposta formativa, mediante a unidade orgânica entre o caráter laboral e a escola, aparece dentro da concepção marxista indivíduos livremente associados, o que somente ocorreria com a superação da propriedade privada e do trabalho alienado (id, 1991).

Para Marx, a divisão técnica e social do trabalho na sociedade capitalista gera a alienação do homem em relação ao próprio trabalho e à natureza, desumanizando-o. Ao criar a totalidade de forças produtivas e o domínio do homem sobre a natureza, em um processo contraditório, torna-se inevitável a apropriação dessas forças por parte do homem e o desenvolvimento completo, multilateral de suas faculdades como ser humano em sua 
integralidade. Em Marx, o trabalho assume um caráter formativo com a eliminação do intelectualismo, fomentando a investigação do mundo circundante e preparando as condições para superar a dicotomia burguesa existente entre educação escolar e extraescolar. Essa compreensão repõe os fundamentos das relações laborais e educativas, objeto de vários estudos. A separação entre ensino e trabalho faz da escola uma instituição "morta".

Marx une o ato produtivo ao ato educativo, explicando que a unidade entre a educação e a produção material deveria ser admitida como meio decisivo para emancipar o homem. Nessa concepção, o ensino politécnico compreende dois níveis que não podem ser separados, emergindo do estudo teórico e do trabalho prático, no ato de transmitir os conhecimentos e nas capacidades técnicas indispensáveis à compreensão dos processos de produção. Esse ensino deveria colocar em evidência o caráter social do trabalho e - dentro da perspectiva de uma sociedade sem classes - estimular a associação livre dos indivíduos, coordenar e planificar o processo social da produção. Segundo Marx e Engels, na sociedade capitalista a educação é um elemento de manutenção da hierarquia social, ou o que Gramsci denominou de instrumento da hegemonia ideológica burguesa.

Uma das possibilidades de viabilizar a superação das dicotomias existentes reside na formação omnilateral, que levaria o ser humano a desenvolver-se em uma perspectiva abrangente, isto é, em todos os sentidos. Essa unidade, segundo o marxismo, fundamentase no tripé básico da educação para todos, que corresponderia ao ensino intelectual (cultura geral), desenvolvimento físico (ginástica e esporte) e aprendizado profissional polivalente (técnico e científico).

$\mathrm{Na}$ última década do século passado, as discussões acerca da aplicabilidade do princípio de vinculação estudo e trabalho exerceram significativa influência na educação cubana. As modificações sociais e econômicas em curso na sociedade e o "período especial" desencadearam um intenso debate sobre questões teóricas que permaneciam latentes durante anos. A escola cubana está centrada na preparação do indivíduo para assimilar as regras da emulação socialista apoiadas em estímulos morais, o que pressupunha um vínculo entre estudo e trabalho como parte integrante do currículo, em todos os níveis. Entretanto, o sistema educativo cubano integrado por instituições tais como a escola, a família e as organizações de massa, dentro de um conceito dialético de formação do homem, não corresponderia integralmente às exigências na formação de valores como a autodisciplina e a responsabilidade. A escola, em particular, apresentava lacunas na formação adequada de indivíduos verdadeiramente motivados à prática laboral. Esse fenômeno atingiria, particularmente, a geração mais jovem nascida após a Revolução, sem memória existencial do passado, acostumada a receber os serviços propiciados pelos organismos estatais, com pouco esforço. Paradoxalmente, muitas das conquistas ocorridas após a Revolução, como a garantia de emprego, os serviços médicos e educacionais gratuitos, o baixo preço das tarifas de transporte e dos programas culturais, enfim, as políticas de distribuição eqüitativa foram consideradas fatores de acomodação e indisciplina. Na construção de uma consciência humana superior, muitas considerações sobre o envolvimento educativo e as políticas de estímulo para elevar a produtividade do trabalho e a qualidade no âmbito do socialismo foram tecidas. No dizer de Castro Ruz (1989, p. 35), "o erro está em crer que o homem só se move por estímulos materiais e que as grandes obras da história só se fazem mediante tais estímulos".

A escola cubana converteu-se em politécnica e profissionalizante a partir do triunfo da Revolução, porém essas concepções, matizadas pelo Período Especial na década de 90, foram se mesclando a ponto de tornar difícil precisar uma fronteira entre elas. Entretanto, de acordo com Cerezal Mezquita (2004, p. 79), é fundamental estabelecer limites entre os dois conceitos para focalizar o ensino politécnico e laboral: 
- O caráter politécnico do ensino é o conjunto de atividades que possui em sua base os fundamentos científicos gerais da técnica contemporânea e o desenvolvimento de uma cultura tecnológica, com todo o seu progresso e em todas as suas aplicações. A politecnia pressupõe uma sólida formação básica que contribua para superar a dualidade tradicionalmente existente entre a formação técnica e a geral, na perspectiva de qualificação integral e crítica.

- O caráter laboral do ensino é o conjunto de conteúdos para a solução de problemas da vida social, que permite desenvolver a orientação profissional, o respeito aos hábitos de conduta laboral, valores e normas de relação com o mundo, em que o indivíduo pense e atue criativamente.

Nas palavras de Castellanos Simons (2001, p. 2), "Cuba está no mundo e com o mundo, sendo parte integrante da sociedade planetária, que surgiu com o novo milênio", portanto, sujeita aos fenômenos mundializados. Assim, o cumprimento do princípio básico da educação cubana de integração do estudo ao trabalho buscou novas concepções, fundamentadas em necessidades econômicas, porém imbricadas a propósitos formativos.

No dizer de Ruiz Aguilera (2003, p. 23), a escola cubana está orientada pelo princípio de que todos os fenômenos e processos dos quais dependem os objetivos, os conteúdos e a organização da educação, assim como o processo educativo em si mesmo, são ações objetivas. Sendo assim é necessário abarcar dialeticamente as regularidades, segundo as quais transcorrem esses processos e a forma de como influir sobre elas. O ser humano se apropria do produto do desenvolvimento histórico-social fundamentado na cultura, o que permite defini-lo como personalidade social e cultural, sem que isso signifique que se desconheça o aspecto biológico e o papel da genética.

Voltada para o século XXI, a educação está comprometida em preservar a cubanía e a identidade nacional, com vistas à formação do homem e à cultura em sua relação dialética. A relação entre teoria e prática encontra sua máxima expressão no princípio martiano de vinculação do estudo com o trabalho, tal como escreveu o herói nacional. A relação que estabelecera $\operatorname{Martî}^{2}(1975$, t. 8 , p. 288) entre cultura, educação e emancipação - ser culto é o único modo de ser livre -, complementada com os pressupostos do Movimento 26 de julho, serviu de base para a concepção de um sistema de Educação orientado por novos fundamentos. Para Álamo de Joy (1960, p. 74), prevaleceu a concepção martiana: "Las revoluciones son estériles, cuando no se firman con la pluma en las escuelas y con el arado en los campos".

\section{A FORMAÇÃO DE PROFESSORES GENERALISTAS INTEGRAIS}

Estudos coordenados pelo Instituto Central de Ciências Pedagógicas - o ICCP -, a partir de 1999, reconheceram que os impactos das transformações sociais e econômicas, no início deste século, suscitavam a reavaliação do papel da escola e dos professores. $\mathrm{O}$ problema fundamental, que deveria ser resolvido no âmbito do SNE, seria transformar a Escola Secundária Básica, - a ESB -, para os alunos entre 13 e 15 anos, considerada o elo mais fraco das instituições escolares cubanas. Com base na concepção dialética do estudo das contradições, que determinariam a necessidade de mudanças, dois fortes processos simultâneos foram implementados: inovar as características escola cubana e formar um novo professor. De acordo com Rojas Arce (2005, p. 5), no período letivo de 1999-2000, como resposta aos problemas que se manifestavam na ESB, entre eles a manifestação de uma escola tradicionalista, com tendências à mera reprodução de conhecimentos, à desmotivação pela forma de organizar o ensino-aprendizagem e ambientes excessivamente diretivos por parte dos docentes, o Ministério da Educação empreendeu um processo de transformações, priorizando o fortalecimento da interdisciplinaridade. 
No debate mundializado sobre as reformas educacionais, frequentemente se enfatizam as reformas fundamentadas nos chamados componentes impessoais da didática, entendidos como os conteúdos, os objetivos, os métodos e a avaliação Todavia, em meados de 2001, quando das origens da nova proposta para a ESB cubana, a visão retrospectiva das campanhas de formação emergente indicava que "a essência dos câmbios é a transformação dos professores" (VALLE LIMA, 2003, p. 26). O cerne do modelo destacava o papel do maestro como educador e descortinava complexidades inovadoras, uma vez que nas mudanças pretendidas o docente não poderia mais dispor de todo o saber e sua função estaria centrada em guiar o aluno na busca de conhecimentos. Os fundamentos da reforma apontavam dificuldades em educar fora de situações concretas e de realidades definidas, evidenciando, assim, a importância da formação em serviço. A profissão de professor combina sistematicamente elementos teóricos com situações práticas reais. Por essa razão, a ênfase na prática, como atividade formadora, aparece como exercício fundamental para o futuro educador. A busca de um professor que atenda às necessidades formativas em uma escola voltada às novas características do mundo contemporâneo não é tarefa simples, uma vez que a identidade profissional se constrói a partir da significação social da profissão, do repensar os modelos tradicionais e do entendimento que cada professor confere à atividade docente no cotidiano, como ator e autor social, com seus valores e seus anseios. A escola é o locus da ação, em que os docentes reinventam significados de construção da realidade.

Segundo Rojas Arce (2005, p. 10), para dar resposta aos problemas que afetavam a qualidade da educação, em particular os relacionados à individualidade no processo educativo, implementou-se a idéia de formar os professores generalistas integrais - os PGIs - capazes de ministrar todas as disciplinas, exceto Inglês e Educação Física, a um grupo de 15 estudantes, convertendo dessa forma o professor em um conselheiro, conhecedor do meio familiar do aluno, de suas perspectivas e dificuldades. De acordo com a proposta, o maestro polivalente deveria acompanhar o mesmo grupo de alunos, do sétimo ao nono grado, o que asseguraria o pleno domínio de suas características, a atenção particularizada de seus problemas, além da possibilidade de compartilhar o desenvolvimento de sua personalidade em cada etapa. O processo de entrega pedagógica, como maneira de garantir que ao transitar pelo sistema o estudante seja atendido em suas dificuldades, deveria organizar-se com tempo suficiente. Para esse fim, o "expediente acumulativo do escolar", um relatório escrito, elaborado pelos diversos professores, acompanha o aluno desde o seu ingresso no sistema formal de educação, onde estão registrados todos os dados significativos do estudante, inclusive as variações do estado de saúde, as características do meio familiar, os avanços e peculiaridades no campo da aprendizagem.

Dentro do projeto, as sedes universitárias, cada qual vinculada a um conjunto de escolas, passariam a ser os locais onde, aos sábados, os graduandos desenvolvem atividades acadêmicas e recebem orientações voltadas às práticas docentes, sob orientação dos Institutos Superiores Pedagógicos. No início do novo milênio, Cuba dispunha de 16 institutos universitários, tendo por objetivo capacitar os professores para todos os níveis do sistema educacional (CUBA, 2005).

No ano de 2001, tomou-se a decisão de proceder, em caráter experimental, à formação dos professores generalistas integrais para a educação secundária. "Tratava-se então de formar um maestro dentro de uma nova concepção do processo educativo, convertendo-o em detonador das mudanças necessárias" (ROJAS ARCE, 2005, p. 6). Com base em pesquisas realizadas nas ESB "Yuri Gagárin", situada na Província de Havana, e na ESB “José Martî" de Havana Velha (ibid., p. 9), os Institutos Superiores Pedagógicos 
iniciaram a formação massiva do novo tipo de professor, trabalhando com jovens egressos do ensino médio, que em um ano receberiam a preparação requerida para incorporar-se de maneira direta às práticas docentes. Ao mesmo tempo, foi necessário preparar os licenciados nas diferentes especialidades, já em exercício, para desempenhar o papel de tutor, que atuaria de maneira direta na orientação dos professores generalistas integrais, cujas características pessoais, profissionais, carências, atributos, potencialidades e possibilidades, ele deve conhecer. Inserido nessa problemática, o projeto tratou de conciliar, dentro do contexto político-social do país, a formação do professor, harmonizando dois campos que tradicionalmente apresentam uma considerável tensão: o inicial e o contínuo. No modelo anterior, os professores se formavam nos Institutos Superiores Pedagógicos, em que eram alunos, e depois vinham para as escolas como professores, o que criava certa tensão de como encaminhar as práticas em classe. Em Cuba, sempre se deu importância à formação em serviço e à superação profissional durante a carreira, mas agora seria diferente, porque se eliminou esse estranhamento do jovem ao passar por um processo adaptação e os conflitos para se inserir na escola.

Em julho de 2002, o ato de graduação dos primeiros 89 professores generalistas integrais, conhecidos como Los Valientes, configurou-se como uma reedição das campanhas alfabetizadoras da década de 60. Nessa ocasião, foi anunciado que mais 4.500 estudantes ingressariam na Escola "Salvador Allende", em Havana, para um novo curso. Desde o ano letivo de 2002-2003, tornou-se prática usual esse modelo de formação docente. Conforme Gómez Gutiérrez (2005, p. 8):

- O primeiro ano da carreira universitária, de caráter intensivo, com 2.200 horas-aula de formação, garante a preparação inicial, que permitirá aos estudantes fundamentar sua prática docente na escola.

- Do segundo até o quinto ano da carreira, com a orientação de um tutor, o PGI/estudante é radicado em uma escola, com a concepção de microuniversidade, obtendo o título de Licenciado em Educação, na especialidade Professor Generalista Integral.

Dos cursos de formação dos professores generalistas integrais incorporaram-se 12.553 maestros às ESBs, para o ano escolar de 2004-2005. Esse nível de ensino contava, ainda, com 26.368 professores graduados, que se converteram em professores generalistas integrais, - PGIs -, sempre considerando a aceitação voluntária na mudança de perfil. Em agosto de 2005, mais 4.980 professores iniciaram sua formação (CASTRO RUZ, 2005).

O cumprimento do princípio básico da pedagogia cubana de vincular o estudo ao trabalho buscou, de forma renovada, estar em sintonia com os avanços tecnológicos que invadiram as classes - televisão, vídeo e computador - e introduzir mudanças curriculares. Além de fomentar a dimensão prática de diversas áreas, não apenas nas aulas ou por meio de conteúdo das disciplinas, o enfoque laboral do ensino deveria envolver além de conhecimentos, valores e normas de conduta. A TV educativa, em rede nacional, passou a emitir programas de Geografia, Biologia, Química, Formação de Valores, Educação Artística e Educação Laboral e os vídeos, disponíveis nas escolas, a trabalhar com Espanhol, Matemática, História e Física. A coleção El Navegante, utilizada atualmente, é composta por dez softwares educativos, que tratam de temas relacionados às disciplinas de Espanhol, Matemática, Inglês, História de Cuba, História Antiga e Média, Educação Artística, Informática e Ciências Naturais, inspirados em uma conceituação integradora de conteúdos do nível secundário. Para o início do ano escolar de 2003-2004, os programas de computação beneficiavam cem por cento das matrículas, com 46.290 computadores instalados em unidades de educação básica, incluindo as rurais, para o que foi necessário 
eletrificar com coletores solares 2.368 escolas, das quais 93 contavam com apenas um aluno (CASTRO RUZ, 2005).

O trabalho de cooperação entre os maestros, com um grupo maior de alunos, assumiu importância ao se tomar a decisão, em 2002, de generalizar o novo modelo de ESB em todo o país, diante da possibilidade de insuficientes salas de aula para acolher grupos isolados de quinze alunos, como se concebeu na idéia original. Foram criadas classes de trinta ou de quarenta e cinco alunos, mantendo-se o princípio de um professor responsável por quinze alunos. Dessa maneira, desenvolveu-se o conceito de trabalho cooperado, a modalidade de organização mediante a qual os PGIs interagem nas tarefas de planificar e executar o processo educativo. A formação de um coletivo de professores, para direção do processo de ensino-aprendizagem, manifesta-se na presença dialética e singular de cada elemento. Os docentes, diante da possibilidade de atingir um ambiente de interdependência produtiva e colaboração, deveriam procurar desenvolver um "trabalho integrado para a distribuição de ações adequadas, visando lidar com as dificuldades" (ROJAS ARCE, 2005, p. 10).

O período escolar em tempo integral nas ESBs tem início, aproximadamente, às $7 \mathrm{~h} 30 \mathrm{~min}$, e conclusão às $16 \mathrm{~h} 30 \mathrm{~min}$. $\mathrm{O}$ objetivo da dupla jornada é oferecer espaços para o tratamento diferenciado a cada aluno. O horário escolar, que deve garantir o planejamento de atividades político-ideológicas, laborais, esportivas, culturais e recreativas, é variável no decorrer do curso. Durante as aulas de Inglês, Computação, Esportes e Educação Física, os PGIs realizam encontros de orientação com seus tutores. A aplicabilidade do princípio de integração do estudo com o trabalho deve relacionar-se com os conhecimentos que professores e alunos possuem, adquiridos através de todas as disciplinas, sob a responsabilidade do coletivo escolar. Para lograr essa cultura laboral é necessário que a educação para o mundo do trabalho seja um componente inseparável da educação geral. A inserção de práticas voltadas para a questão laboral, dentro do modelo para a ESB, propõe a descentralização da gestão educativa e o empoderamiento de todos os protagonistas que integram a comunidade (CASTELLANOS SIMONS, 2001, p. 14).

O desconcentrar caracteriza-se, no projeto, pela implantação das sedes universitárias organizadas por bairros, o que representa um fator de valorização do entorno escolar, mantendo a concepção centralizadora no tocante aos objetivos e fins, com o sentido de "preservar a unidade do sistema", de acordo com o Mined (CUBA, 2003). Para tal, devem ser ponderadas, em cada caso, as possibilidades de vinculação com o trabalho, que existem na própria escola, nas empresas e nas indústrias locais, assim como outros centros de atividades sociais. Durante o desenvolvimento das práticas é necessário motivar as pesquisas e as propostas para a utilização dos conhecimentos assimilados anteriormente e a busca de novas informações.

Ao analisar e discutir as propostas de trabalho, o professor deve propiciar que as possíveis soluções partam do aluno, de forma que se estabeleça um compromisso para o comprimento da tarefa. A definição de atividades é diversificada para cada grado e para cada escola. As variantes do processo incluem a atenção às hortas de auto-abastecimento, trabalho de manutenção e reparação do mobiliário escolar, carpintaria, funilaria, confecção e consertos de uniformes escolares, além das tarefas de limpeza das instalações escolares. Aos sábados, os alunos são mobilizados em campanhas, entre elas as BELCA, que são as Brigadas Estudantis de Luta Contra o Mosquito Aedes transmissor da dengue, tarefa que executam na companhia de funcionários responsáveis por esse serviço e dos PGIs. Com frequiências mensais, os alunos das ESBs realizam visitas aos centros de interesse obreiro. Em Havana, as visitas são realizadas no Palácio Central de Pioneiros "Ernesto Che Guevara", situado no Centro Recreativo-Cultural "Parque Lênin", contando com mais de 
mil círculos de interesse, que promovem 179 especialidades de formação profissional e vocacional. As atividades de formação se distribuem por áreas, entre as quais, salas de eletrônica, oficinas de artes, enfermaria modelo, laboratórios de ciências naturais, operações militares, projetos de centrais açucareiras e cuidados com animais.

O trabalho produtivo agrícola é outra forma de atividade laboral, que a partir do nível da ESB tem duas modalidades: a escola al campo para os centros urbanos e a escola en el campo para os centros localizados em zonas rurais com regime de internato. Para as ESBU, ou seja, as urbanas, durante a permanência anual de quatro a sete semanas no campo, juntamente com o trabalho nas lavouras, são aprofundados os aspectos teóricos práticos relacionados com as técnicas agrícolas, assim como as aplicações nas diferentes disciplinas. Todos são orientados a organizar seus pertences, ajudar no preparo da alimentação e nas tarefas de limpeza dos cômodos. Nesse período, em que as aulas são suspensas, os alunos e os PGIs permanecem em alojamentos preparados com a finalidade de viabilizar as atividades em tempo integral. No caso das ESBEC, as escolas en el campo, que se encontram localizadas junto a unidades produtivas, a força de trabalho estudantil é mobilizada em dependência da idade, sexo e possibilidades no cultivo de cítricos, café, tabaco, verduras, hortaliças e vegetais no período da manhã e pelas tardes as aulas se desenvolvem nos centros escolares. Os alunos em sua maioria são egressos de famílias que vivem distantes das cidades. Essas escolas no campo contam com laboratórios de informática, bibliotecas, quadras de esporte, enfermaria e todas as demais instalações necessárias para assegurar a permanência dos alunos em situação favorável a uma educação de qualidade (CEREZAL MEZQUITA, 2004).

\section{CONSIDERAÇÕES FINAIS}

Em meio aos caminhos e às soluções propostas ao modelo implementado nas escolas Cuba, existem dilemas e tensões inscritos na problemática geral do país, sobretudo no conflito entre a lógica da emancipação e da regulação. O ensinar exige intensa reflexão, porque a identidade do professor apenas pode se tornar clara ao analisarmos a profundidade de seu raio de ação e as formas de transformar a própria prática docente. A concepção atual aponta para a perspectiva de rompimento com os modelos anteriores, nos quais os maestros, muitas vezes, eram levados a imitar as práticas sugeridas por pesquisadores dos institutos centrais e negligenciar os saberes oriundos de suas próprias vivências. Entretanto, questões importantes sobre "o que" deve ser ensino, "o como" e "os porquês" ainda permanecem num âmbito centralizado, uma vez que o dinamismo do processo ensino-aprendizagem está restrito, sob determinados aspectos, às aulas televisivas e aos programas de computador.

A visão retrospectiva da formação docente em caráter emergencial, nos diferentes contextos que evoluem imbricados ao processo político-social do país, afasta as transformações projetadas do perfil das mudanças com base em formulações que partem do zero, sem recuperar a experiência e as pesquisas disponíveis, desconsiderando as condições reais e específicas de implementação. Ao movimento global, pautado pela inauguração de novos projetos a cada gestão, que muitos denominam "onda reformista", pode ser debitado o desperdício de importantes recursos, uma vez que a descontinuidade ignora o esforço empreendido, o levantamento de dados e a análise de relações do saber historicamente construído. Muitas das reformas pretendidas não chegam às salas de aula ou não alteram em profundidade as suas práticas cotidianas. As chamadas inovações são introduzidas, sem uma avaliação dos erros e avanços das lições que poderiam ser extraídas dos programas que "caíram da moda". As experiências educativas são próprias de cada lugar e não é um processo simples transferir inovações. Tal enfoque tende a salientar um aspecto propício às 
mudanças nas escolas cubanas - as raízes de reflexão dialética fincadas nas circunstâncias históricas locais -, o que possibilita abarcar com mais facilidade as incoerências dos modelos anteriores aos projetos desenvolvidos neste novo milênio, a atenção voltada aos possíveis desacertos e à consciência crítica de repará-los com prontidão. As conclusões acumuladas em retrocessos e avanços, aliadas ao resgate das experiências coletivas no campo educacional, desde a década de 60 , representam um fator decisivo na efetividade das transformações.

O conflituoso entrelaçamento da escola com o trabalho e sua inserção no campo dos valores aponta a transformação pretendida em Cuba como opositora aos modelos que reduzem a educação a um simples problema setorial, com visível desprezo pelo papel da escola na formação do homem. Ainda que antagônicas, nas concepções das duas tendências, - a dos países centrais sob a fórmula do neoliberalismo e a do modelo almejado no socialismo -, a escola é altamente valorizada como o locus ideal da concretização dos objetivos no plano político-social. Cabe nesse aspecto, salientar que os verdadeiros fins - o sentido teleológico - da educação encontram-se, verdadeiramente, em arenas contrárias. $\mathrm{Na}$ tentativa de problematizar essas idéias, destaco o posicionamento de Pérez Lemus (2001, p. 32), que aponta a ótica neoliberal como mera defensora da educação para o trabalho voltada aos interesses do mercado, mas tratando de conformar as propostas com uma "tecnologia humanística", entre outros "edulcorantes", que resultam num humanismo adicionado de fora, alheio à essência daquilo a que a educação se propõe.

Com globalização, os novos padrões impostos ao trabalhador, associados ao uso de tecnologias sofisticadas, apenas as "torneiras da instrução" foram um pouco mais abertas, como pondera Freitas (2004, p. 93). A consequência mais nefasta dessa concepção é a forma pela qual o jovem passa a considerar a vida laboral, encarada sem elementos motivadores capazes de enriquecê-lo como ser humano. A escola é local de conflito, pela simples razão de que sua função social é dupla - preparar trabalhadores e formar cidadãos. Nas economias de mercado, essas duas funções acabam enredadas num antagonismo complexo e insolúvel, uma vez que a formação do cidadão implica no aprendizado da igualdade de oportunidades e de possibilidades, elementos que frequientemente são incompatíveis com a preparação para o trabalho num sistema dominado pelos interesses do capital.

Ainda que a pedagogia socialista em Cuba seja a manifestação das formulações do marxismo-leninismo em matéria de humanismo e da elevação da capacidade intelectual do homem, a ação evolutiva da economia em Cuba, a passividade imposta aos jovens em seu processo de socialização e a influência de padrões externos, sobretudo da comunidade cubana residente nos Estados Unidos, conformou um modelo de bem-estar embasado em elevados níveis de consumo e com tendências à mentalidade de consumidor acima da consciência de produtor, problemas que dificultam a consolidação da escola e do trabalho na esfera dos valores. A adaptação de parte considerável da população cubana ao mercado informal, compatível com níveis de escolaridade mais baixos, forçou as expectativas no sentido negativo em relação à escola e à importância da educação dentro da sociedade. $\mathrm{O}$ próprio sentido do trabalho, como valor, foi afetado a partir da segunda metade dos anos 90, quando ocorreram câmbios socioeconômicos, entre eles a diversificação no caráter das propriedades e das novas formas de produção. Entretanto, os fundamentos da educação cubana ainda estão fortemente influenciados pelo ideário pedagógico de Martí e pelas contribuições teóricas de Marx e Engels sobre o trabalho e o coletivismo, no processo de aplicação do materialismo dialético como método filosófico, em suas dimensões históricas, econômicas, políticas, sociais e técnico-científicas. 


\section{Bibliografia}

ALARCÓN DE QUESADA, Ricardo. La Universalización de la universidad por un mundo mejor. In: ENCUENTRO DE EDUCACIÓN SUPERIOR. Habana, 2006.

CASTELLANOS SIMONS, Doris. Aprender en la escuela: una concepción desarrolladora. Habana: ISP "Enrique Varona", 2001.

CASTRO RUZ, Fidel. Por el camino correcto. Habana: Política, 1989.

Discurso pronunciado por el Presidente de Cuba Fidel Castro Ruz. In: ACTO DE GRADUACIÓN DE LA ESB EXPERIMENTAL J. MARTÍ, 23 jul.2005. Tabloide Granma, n.6, 2005.

CEREZAL MESQUITA, Julio. El Carácter laboral y politécnico de la enseñanza en la secundaria básica. In: GARCÍA RAMIS, Lisardo Propuesta curricular para la ESB actual. Habana: Pueblo y Educación, 2004. p.75-87.

CUBA (República de). Ministerio de Educación. Informe 2005. Disponível em: <http://www.rimed.cu/pedagogicos.asp\#.>. Acesso em: 12 set. 2005

Proyecto de escuela secundaria básica. Habana, vers. 7 abril 2003.

FREITAS, Luiz Carlos de. Neotecnicismo e formação do educador. In: ALVES, Nilda (org.) Formação de professores: pensar e fazer. São Paulo: Cortez, 2004.

KOHAN, Nestor. La Vitalidad del pensamiento radical latinoamericano. In: HART DÁVALOS, Armando. Marx, Engels y la condición humana. Habana: Ciencias Sociales, 2005a. p.11-29.

GÓMEZ GUTIÉRREZ, Luis. “Cuba: una revolución en la educación”. In: PEDAGOGÍA 2005. Encuentro por la unidad de los educadores. Habana, 2005.

MACHADO, Lucília R. de Souza. Socialismo, trabalho e educação: o trabalho como princípio educativo em Cuba. B. Horizonte: 1991. Tese (livre-doc.) Universidade Federal de Minas Gerais.

MANACORDA, Mário A. Marx e a pedagogia moderna. São Paulo: Cortez, 1991.

O Princípio educativo em Gramsci. Porto Alegre: Artes Médicas, 1990.

MARTÍ, José. Obras completas. La Habana: Ciencias Sociales, 1975.

PÉREZ LEMUS, Leonardo. Educación laboral y siglo XXI. Revista Educación. Habana: Segunda Época, n.103, p.30-34, mayo-ago. 2001.

ROJAS ARCE, Carlos. La Experiencia cubana en la realización del cambio educativo en la secundaria básica. In: PEDAGOGÍA 2005. Resumen. Habana, 2005.

RUIZ AGUILERA, Ariel. Teoría y práctica curricular. Habana: Pueblo y Educación, 2003.

VALLE LIMA, Alberto et al. La Transformación educativa: consideraciones. Habana: Pueblo y Educación, 2003.

UNESCO. Educación para todos, el imperativo de la calidad: informe da la EPT en el mundo. Paris: Organización de las Naciones Unidas, 2005. Disponível em: < http://portal.unesco.org/education/es/ev.php>. Acesso em: 20 maio 2010.

\footnotetext{
${ }^{1}$ Professora de Física da UNISANTOS, mestre em Educação.

${ }^{2}$ In: Maestros ambulantes. Nova York: maio de 1884.
}

Recebido em: $\quad$ 12/12/10

Aprovado em: $\quad 05 / 02 / 11$ 